Illinois State University

ISU ReD: Research and eData

Theses and Dissertations

3-12-2015

\title{
When Lovers Become Friends: Rules of Post-Dissolutional Friendships
}

Annelise Nicole Ewing

Illinois State University, anewing@ilstu.edu

Follow this and additional works at: https://ir.library.illinoisstate.edu/etd

Part of the Communication Commons

\section{Recommended Citation}

Ewing, Annelise Nicole, "When Lovers Become Friends: Rules of Post-Dissolutional Friendships" (2015). Theses and Dissertations. 343.

https://ir.library.illinoisstate.edu/etd/343

This Thesis is brought to you for free and open access by ISU ReD: Research and eData. It has been accepted for inclusion in Theses and Dissertations by an authorized administrator of ISU ReD: Research and eData. For more information, please contact ISUReD@ilstu.edu. 


\title{
WHEN LOVERS BECOME FRIENDS: \\ RULES OF POST-DISSOLUTIONAL FRIENDSHIPS
}

\author{
Annelise N. Ewing \\ 72 Pages \\ May 2015 \\ This study explores the communication between former dating partners that have \\ chosen to remain friends following the termination of a romantic relationship. Post- \\ dissolutional friendships are relationships with a legacy of romantic behavior turned into \\ a friendship. Rules are a guide to behavior in relationships. Rules for both romantic \\ relationships and friendships exist. This study discovered what rules guide the behavior \\ in post-dissolutional friendship and how they relate to feelings of closeness in the \\ relationship.
}


WHEN LOVERS BECOME FRIENDS:

RULES OF POST-DISSOLUTIONAL

FRIENDSHIPS

ANNELISE N. EWING

A Thesis Submitted in Partial

Fulfillment of the Requirements

for the Degree of

MASTER OF SCIENCE

School of Communication

ILLINOIS STATE UNIVERSITY

2015 
Copyright 2015 Annelise N. Ewing 
WHEN LOVERS BECOME FRIENDS:

\section{RULES OF POST-DISSOLUTIONAL}

FRIENDSHIPS

ANNELISE N. EWING

COMMITTEE MEMBERS:

William Cupach, Chair

Sandra Metts

Kevin R. Meyer 


\section{ACKNOWLEDGMENTS}

I wish to thank, first and foremost, my chair and mentor, Dr. William Cupach. He has guided and supported me throughout my entire thesis process. Before I arrived at Illinois State University, I admired the work of Dr. Cupach and was thrilled by the opportunity to be a student of his. He is a prolific scholar who has influenced my work as well as the work of thousands of other communication scholars. Not only has he guided me as a student, he has taught me what it means to be a contributing member of this discipline. He has encouraged me every step of the way and has made me a better pupil, teacher, and communication scholar. To Dr. Cupach, I am eternally grateful.

In a similar manner, I would like to thank Dr. Sandra Metts for encouraging me throughout the thesis process and all of graduate school. I am incredibly lucky to have this scholar on my committee as well. She has contributed copious amounts of research into our discipline. Dr. Metts is one of the most nurturing people I have ever had the privilege to know. She has supported my goals both academically and personally. She has offered me excellent feedback and suggestions for my thesis and general communication scholarship that has improved the overall quality of my work.

Additionally, I would like to recognize Dr. Kevin Meyer for being on my committee. Had it not been for Dr. Meyer, I may have never decided to attend Illinois State University. He was the most influential person in my decision to attend graduate school at Illinois State, and for that, I cannot thank him enough. Kevin is an incredibly 
intelligent scholar that balances a huge workload with grace. He is truly a model instructor.

Thank you to my family for the love, backing, and guidance throughout my schooling. My parents, Rob and Kathy have assisted me every step of the way and have made me the woman I am today. I would like to offer a special thank you to Megan Koch and my extended family of the Illinois State Forensics Team. They have been a huge encouragement throughout my graduate school process. The team, especially, has been a support system for me. The students have pushed me as a coach, educator, and student. Thanks for all the laughs and love.

Lastly, I would like to thank the School of Communication for an incredible two years. Specifically, Patty Franz has been an amazing guide throughout my time here. She has such a special relationship with each and every graduate student. She acts as a caretaker for us and I couldn't have done it without her. I offer my gratitude to the staff of the School of Communication and my cohort for their unwavering encouragement and friendship. I am humbled to have worked with such a remarkable group of scholars. To them I would like to say, thank you for this privilege. 


\section{CONTENTS}

Page

ACKNOWLEDGMENTS $\quad$ i

CONTENTS

TABLES $\quad \mathrm{V}$

CHAPTER

I. INTRODUCTION 1

II. REVIEW OF LITERATURE 4

Post-Dissolutional Relationships 4

Post-Dissolutional Friendships $\quad 5$

Creation of Post-Dissolutional Friendships $\quad 7$

Stages in Post-Dissolutional Friendships 9

Maintenance of Post-Dissolutional Friendships 13

$\begin{array}{ll}\text { The Rules Perspective } & 14\end{array}$

Rules in Romantic Relationships $\quad 16$

Rules in Friendship 19

Rules in Post-Dissolutional Friendships 22

$\begin{array}{ll}\text { III. METHOD } & 25\end{array}$

$\begin{array}{lr}\text { Participants } & 25\end{array}$

$\begin{array}{ll}\text { Procedure } & 26\end{array}$

$\begin{array}{ll}\text { Data Analysis } & 30\end{array}$

IV. RESULTS

Research Questions $\quad 32$

Hypotheses $\quad 36$

$\begin{array}{ll}\text { V. DISCUSSION } & 38\end{array}$ 
$\begin{array}{ll}\text { Summary of Findings } & 38\end{array}$

RQ1: Important Romantic Relationship Rules In PDFs $\quad 38$

RQ2: Important Friendship Rules in PDFs 41

RQ3: Rules Distinctly Important to PDFs 42

H1: Importance of Maintenance and Intimacy-Reward Rules 48

H2: Following of Maintenance and Intimacy-Reward Rules 49

H3: Rules and Solidarity $\quad 50$

Implications $\quad 51$

Limitations $\quad 54$

Suggestions for Future Research $\quad 55$

Conclusion $\quad 57$

$\begin{array}{ll}\text { REFERENCES } & 59\end{array}$

APPENDIX A: Highly Endorsed Friendship Rules 62

APPENDIX B: Rules That Were Found to be Very Important
in Causing of the Break-up of a Friendship

APPENDIX C: Survey Instrument $\quad 64$ 


\section{TABLES}

Table $\quad$ Page

1. Rules of Post-Dissolutional Friendships Included in the Current Survey 28

2. Rules Deemed to be Important in Post-Dissolutional Friendships 33

3. Rules Distinctly Important to Post-Dissolutional Friendships 35 


\section{CHAPTER 1}

\section{INTRODUCTION}

Historically, break-ups have been viewed as the ending of communication within a romantic relationship; however, for some couples, a complete termination of interaction with a former romantic partner is not desirable or possible. Recent years have seen the rise of studies exploring post-dissolutional communication, or, simply, communication that happens after the termination of a romantic relationship (Busboom, Collins, Givertz, \& Levin, 2002; Koenig Kellas, Bean, Cunningham, \& Cheng, 2008; Lambert \& Hughes, 2010). Continued communication ultimately shapes how the dyad chooses to reframe their relationship as individuals no longer in a dating relationship. These relationships are known as post-dissolutional relationships (PDRs), and while they come in many variations (e.g., divorcing partners who remain co-parents), this thesis is focused primarily on dating, romantic relationships that have turned into friendships.

While some couples may completely terminate communication after a break-up, some do not want to completely remove each other from their lives. For those former dating couples who wish to remain in contact, they must reframe the nature of their relationship following the termination of the romantic aspect of it in order for it to continue. The partners must negotiate how to interact with each other without the romantic/sexual component that the relationship previously had. The dyad finds 
themselves in a new type of relationship, not just of platonic cross-sex friends or exlovers, but a friendship with a romantic legacy. These relationships are best understood using the label, post-dissolutional friendships (PDFs). Post-dissolutional friendships are a renegotiation of a previous relationship —one in which the individuals know more about each other on a different basis than if they had just been platonic friends. In postdissolutional relationships, former partners may find that they have different goals in mind. Just as any other relationship has norms or rules that regulate behavior of those involved, so too must post-dissolutional friendships. The status of the relationship may become unclear when intentions are not specified after the termination of the romantic relationship. Reducing ambiguity in the relationship requires renegotiation of the boundaries of the relationship. Both partners must be willing to commit to interact in the form of a friendship. Couples must maintain open communication in order for the postdissolutional friendship to flourish. Unfortunately, some relationships cannot continue following a break-up, but for those that do, more research is necessary.

There are many different ways that one could look at the functioning of this type of relationship; however, the rules perspective will be the most fruitful for this study. The rules perspective posits that rules coordinate the behavior of individuals in accordance to the goals and conventions of the relationship in which they are involved (Argyle, Graham, Campbell, \& White, 1979; Cushman \& Whiting, 1972). Rules for behavior exist within all relationships and differ depending on the intentions of the individuals sharing the relationship. Romantic relationships and friendships shape their behavior around a set of agreed upon rules. A few studies have examined the presence of rules within romantic relationships (Baxter, 1986; Jones \& Gallois, 1989). Argyle and Henderson (1984) were 
able to compile a list of friendship rules that dyadic partners adhere to in most situations. Because post-dissolutional friendships have elements of both the previous romantic relationship and friendship, it would seem logical that post-dissolutional friendships would share some of the same rules as friendship and romantic relationships while adhering to new ones as well. This study seeks to discover which rules are salient in a post-dissolutional friendship.

Previous relationships lay the basis for understanding current and future relationships. The understanding of the role of rules in relationships becomes especially important when reflecting on past relationships and applying that knowledge to future relationships. The failure or success of past relationships becomes a proving ground for how individuals choose to ultimately shape their lasting romantic relationships.

Post-dissolutional friendships are a relatively new communication research area and as such, not all facets of the relationship have been studied. Because rules facilitate the maintenance and quality of all relationships, it is important to identify which rules are important in post-dissolutional friendships. Post-dissolutional relationships, and more specifically post-dissolutional friendships, can be best understood by first reviewing past literature on these relationships. 
CHAPTER II

\section{REVIEW OF LITERATURE}

Past studies have focused on the creation of and reasons for maintaining postdissolutional relationships. These studies must be reviewed to understand the state of research in post-dissolutional friendships. First, the creation, stages and maintenance of post-dissolutional relationships will be reviewed. Then, the rules perspective will be explained in both romantic and friendship relationships before finally applying the rules perspective to post-dissolutional friendships.

\section{Post-Dissolutional Relationships}

The phrase "we can still be friends," is often uttered during a break-up to soften the blow of the ending of a romantic relationship, and for some sets of partners, this promise is actually kept. Many people whose relationships have been terminated will, in one form or another, continue to communicate with one another afterwards (Koenig Kellas et al., 2008). Former romantic partners may choose to continue to correspond for a multitude of reasons: shared resources, children, or a desire to remain friends. Often the dyad chooses to redefine a relationship after the romantic nature of their relationship is over (Koenig Kellas et al., 2008). Following the dissolution of romantic relationships, expartners may find themselves desiring a new type of connection. Former partners who choose to maintain contact with their ex-partners often times structure this new 
association as a "friendship" (Schneider \& Kenny, 2000). This type of post-dissolutional relationship can be classified as a post-dissolutional friendship.

\section{Post-Dissolutional Friendships}

Post-dissolutional relationships may take the form of a friendship because of the interpersonal connection the ex-romantic partners still share (Busboom et al., 2002). Often, couples describe their romantic partners as their "best friends" and wish to keep the camaraderie between the two intact after the termination of the romantic element. Metts, Cupach, and Bejlovic (1989) elaborate on this concept and explain:

Previously established schemas for relating as friends may facilitate redefinition because uncertainty is relatively low and predictability is relatively high when entering the post-disengagement friendship and/or partners share in common a schema that considers post-disengagement friendship to be a reasonable path for relational trajectories. (p. 270)

In essence, because the dyad has had previous interpersonal experience, the formation of a post-dissolutional friendship may be more easily achieved. However, the redefinition of these relationships will require new ways of communication. Schneider and Kenny (2000) explain that relationships with a history of romance may make transitioning to a friendship difficult "aside from still wanting to share in physical intimacy, the general desire to continue a romantic relationship may likely be present in relationships between ex-romantic partners" (p. 455). In order for the new relationship to flourish, the way in which the former partners communicate must be altered to respect new boundaries.

Schneider and Kenny (2000) suggest that post-dissolutional relationships are distinct from both strictly platonic friendships and romantic relationships. Lannutti and 
Cameron (2002) found participants of their study, who were involved in a postdissolutional relationship, reported "moderate amounts of emotional intimacy and interpersonal contact, and low amounts of sexual intimacy" (p. 164) in their postdissolutional friendships. Understandably, romantic relationships are characterized as having more sexual intimacy than post-dissolutional friendships; however, the amounts of emotional intimacy reported in post-dissolutional relationships are usually higher than experienced in strictly platonic relationships (Lannutti \& Cameron, 2002). This difference in emotional and sexual intimacy suggests that, in order for post-dissolutional relationships to succeed, communication must reflect the intimacy needs of the partnership.

Post-dissolutional relationships are similar in both the heterosexual and homosexual community. Lannutti and Cameron (2002) found little difference between heterosexual and homosexual dyads. In both groups, participants reported high amounts of satisfaction with the partnership, moderate amounts of emotional intimacy and interpersonal contact, and low amounts of sexual intimacy in their post-dissolutional friendships. This further supports the distinct qualities that post-dissolutional relationships have compared to strictly platonic relationships, whether the postdissolutional relationship is performed in a heterosexual or homosexual dyad.

Now that post-dissolutional relationships have been broadly defined, postdissolutional friendships must be better understood. To better comprehend the nuances of post-dissolutional friendships the creation of post-dissolutional friendships will be discussed. 


\section{Creation of Post-Dissolutional Friendships}

A romantic relationship reaches a state of decline when one or both partners are no longer satisfied with the relationship. In order to satisfy the needs of both partners involved, something must occur. "If the relationship cannot be restored to its previous status, it must be endured, terminated, or redefined" (Metts et al., 1989, p. 270). Many factors contribute to the creation of a post-dissolutional friendship or lack thereof. Research suggests that the relational variables, shared social networks, being friends prior to the romantic relationship, and disengagement strategy all influence whether or not former dating partners continue their relationship in the form of a post-dissolutional friendship (Banks, Altendorf, Greene, \& Cody, 1987; Metts et al., 1989; Schneider \& Kenny, 2000).

Relational variables influence the extent to which individuals choose to remain friends with a former dating partner. Banks et al. (1987) found evidence that desirability, intimacy, constraint and partner's failure to compromise have an impact on friendship. In particular, high partner desirability was linked to the probability of remaining friends with former dating partners. Echoing the findings of Schneider and Kenny (2000), emotional intimacy within the relationship was also linked to continued friendship. Lastly, constraints (perception that the partner wanted a relationship more serious than the other and consequently was constraining/suffocating the respondent) within the relationship as well as partners' failure to compromise were negatively associated with remaining friends following the disengagement.

Dyads may also choose to remain in contact due to shared social networks. If a large overlap of friends exists between dating partners following the break-up of the 
romantic relationship, they may choose to remain friends to maintain cohesion in the social network. Scholars also assert that being friends prior to the romantic relationship increases the probability of previously dating partners choosing to become friends once again (Metts et al., 1989; Schneider \& Kenny, 2000). Metts et al. contend that dyads who were friends prior to being dating partners were more likely to engage in postdissolutional communication. In Metts et al.'s study, participants reported on a specific romantic relationship that had "changed significantly, either broken up or evolved into a friendship" (p. 270). The former dating partners reported, "having been friends prior to being dating partners facilitated post-disengagement friendship. Both those who initiated the disengagement and those who were recipients of their partners' initiative reported continued, significant, and voluntary affiliation with their partners" (p. 270). Schneider and Kenny (2000) argue that former dating partners who were friends prior to the relationship may be able to make the transition to friendship easily because the partners have a previous knowledge of what it is like to be friends without being romantically involved.

Besides the aforementioned relational variables, research suggests that the communication strategy used during the termination of a romantic relationship is a significant predictor of the existence of a friendship after the break-up (Metts et al., 1989; Schneider \& Kenny, 2000). Metts et al. (1989) found that relationships that involved a high level of psychological and emotional involvement prior to the break-up are likely to use a positive disengagement style (break-up strategy that uses positive language to decrease negative feelings about the relationship) — which could lead to positive postdissolutional communication. If the overlap of friends between dating partners after the 
break-up is significant, disengagers are likely to use a positive tone (attempting to avoid having hard feelings about the break-up), or de-escalation (request for decrease in intensity and commitment but future contact is still possible). These strategies are chosen to expedite the transition from a romantic relationship into a friendship. Banks et al. (1987) also studied disengagement strategies in romantic relationships and found that disengagers were less likely to remain friends with their former partners if they used avoidance (avoiding all contact) tactics (Banks et al., 1987). In their study, Metts et al. (1989) found "for respondents who initiated the disengagement, the use of withdrawal (emotional and physical withdrawal) strategies was negatively associated with redefinition of a romantic relationship into a friendship" (p. 272). There is no doubt that the way in which one disengages from a romantic relationship will affect the potential for communication and possible friendship after (Banks et al., 1987).

\section{Stages in Post-Dissolutional Friendships}

To better recognize how post-dissolutional friendships function, pivotal stages and events in post-dissolutional relationships have been examined. Turning points are relational events that capture a critical event or incident. Turning points can affect the commitment positively or negatively within a relationship. Research suggests that, like traditional relationships, turning points occur in post-dissolutional friendships. Turning points are evaluations of occurrences that give meaning and definition to a relationship (Koenig Kellas et al., 2008). Graham (1997) analyzed turning points and their effect on commitment within post-divorce relationships. She identified 11 turning points within post-divorce relationships: well-functioning binuclear family (successful co-parenting), dysfunctional former spousal relationship (continued fighting and conflict between 
former spouses), life-improving events (favorable changes in quality of life), remarriage of the participant, former spouse remarries, parent-child problems (loss of control parents experience in relation to their children), emotional divorce (letting go of former spouse emotionally, sometimes reported as more painful than legal divorce), relocation (concerns some sort of separation between a parent and their children), personal hardship (encompasses troubles and problems experienced by the participant that were independent of their former spouse or children), participant's second marriage ends in divorce, and former spouse's second marriage ends in divorce. Turning points were associated with commitment in the relationship. Life-improving events, well-functioning binuclear family, and participant remarries were all associated with an increase in commitment. Emotional divorce, dysfunctional former spouse, parent-child problems, personal hardships, relocation, former spouse remarries, and participant's second marriage ends in divorce were all associated with a decrease in commitment (Graham, 1997).

Graham (1997) also identified five trajectory patterns that characterized the postdivorce relationship. The first pattern was "gradual relational progress" and was characterized by slow and steady progression towards a divorce after which the dyad remained friends. The second pattern, "disrupted progress," was marked by a pattern of high hopes for the relationship, interrupted by a bottoming out, and then followed by a steady recovery. The next, "sustained adjustment," was rather unusual and reported few turning points and their commitment level remained relatively unchanged since the time of their divorce. The fourth pattern was "disjointed erratic cycle" and was characterized by lots of fluctuation between highs and lows. The final pattern, "eventual deterioration" 
started out with high hopes but progressed into a continuous decline. These trajectory patterns explain how post-divorce relationships develop. Some trajectories are more volatile and problematic. It can be assumed that these relationships are of lower quality.

Koenig Kellas et al. (2008) examined turning points within non-marital postdissolutional relationships to determine the life cycle of post-dissolutional relationships. Additionally, the authors sought to discover the ways in which post-dissolutional relationship development is related to commitment within the relationship. Using a modified retrospective interview technique, the authors gathered information from participants who chose to answer questions regarding one significant post break-up relationship. Results indicated 10 different significant turning points (in order from most frequently reported to least) in post-dissolutional relationships: negative (re) definition of the relationship (characterized by incidents and interactions that participants reported having a negative impact on post-dissolutional relationship development and perception), positive (re) definition of the relationship (lead to a positive change in the postdissolutional relationship), holding on (suggested that many people were not ready to redefine the romantic relationship into a platonic one), letting go (characterized by the need to let go of the pre-dissolutional romantic relationship), moving on (described extrarelational factors that facilitated separation from the romantic relationship), maintaining contact (referred to maintaining enough contact for ex-partners to stay in touch with each other), break-up (the verbal break-up of the romantic relationship), logistics of uncoupling (the returning of items, moving out of a shared apartment, etc.), ending the post-dissolutional relationship (the complete termination of communication), and romantic reconciliation (partners choosing to get back together in the form of a romantic 
relationship). Many of the participants who made it through at least five of the positive turning points found that they had successful post-dissolutional relationships (Koenig Kellas et al., 2008). The following turning points were associated with the negative redefinition, or decline in commitment, of the relationship: awkward or uncomfortable interaction, arguments, unrequited advances by ex (negative), jealousy-provoked interactions, harassment, ex-partner's new romantic relationship (negative), going downhill, and disappointment in ex-partner. Negative redefinition of the relationship was characterized by incidents and interactions that participants reported having a negative impact on how participants perceived their post-dissolutional relationship. The following turning points were associated with positive redefinition, or increase in commitment, of the relationship: cathartic/reflective talk, becoming friends, best friends, social support, and forgiveness. Positive redefinition of the relationship was defined as a positive change in the perception of the relationship. Not all post-dissolutional friendships are the samethey vary in quality and follow different trajectory patterns. This research adds to the understanding of how significant events affect the commitment within post-dissolutional relationships (Koenig Kellas et al., 2008).

Additionally, Koenig Kellas et al.'s (2008) study revealed four trajectory types (visual patterns associated with participants' turning point analysis) of post-dissolutional relationships: linear process, relational decline, upward relational progression, and turbulent relational progression. Linear process refers to a post-dissolutional relationship that remains relatively unchanged in commitment over time. Relational decline illustrates a downward progression in commitment over time. To the opposite effect, upward relational progression occurs when commitment rises in a post-dissolutional relationship 
over time. The final trajectory, turbulent relational progression, described a tumultuous post-dissolutional relationship, with lots of ups and downs in commitment (Koenig Kellas et al., 2008). Koenig Kellas et al.'s study provided significant contributions to the understanding of the development of post-dissolutional relationships. Trajectory patterns unveil how different post-dissolutional relationships look when commitment levels vary.

\section{Maintenance of Post-Dissolutional Friendships}

Maintenance behaviors serve to sustain the current status or characteristics of the relationship (Argyle \& Henderson, 1985). Busboom et al. (2002) used social exchange theory to describe how post-dissolutional relationships are maintained by arguing that resources, satisfaction with those resources, and barriers were found to contribute to the maintenance or decline of a friendship with a former romantic partner. Resources in this

case were understood to be anything allowing one person to reward another-an object of exchange. The amount of resources is positively correlated with the maintenance of the post-dissolutional friendship. Busboom et al. (2002) also articulated that friendship quality is not just a function of frequency of received resources but also includes the level of satisfaction associated with those resources. The more satisfaction an individual receives from the relationship, the more likely that individual is to maintain that friendship. However, barriers to post-dissolutional relationships exist. Barriers in Busboom et al.'s (2002) study were understood as any “impediments to having a high quality friendship with one's former partner" (p. 221). Barriers to post-dissolutional relationships include limited social support for the relationship as well as the opportunity to take another romantic partner; these are all significant predictors of lower postdissolutional friendship quality (Busboom et al., 2002). 
To fully discern how post-dissolutional relationships function, a clear difference must be established between platonic friends and individuals engaging in a postdissolutional friendship. In both platonic friendships and post-dissolutional friendships the potential for the possibility of romantic desires to emerge is present. Because of the previous romantic component of post-dissolutional friendships, it is not uncommon to experience feelings of jealousy within these relationships. Both parties must navigate how the new relationship will function. It is only understandable that jealousy would arise in unfamiliar situations. Jealousy refers to the belief or suspicion that what has been a source of previous devotion is in danger of being lost (Salovey \& Rodin, 1989). Schneider and Kenny (2000) found that people found themselves being more jealous and critical of a friend's relationship more in their relationships with a former partner than with a platonic friend. Schneider and Kenny maintain that one reason that people would want to remain friends with an ex-romantic partner is for the possibility of a flame being reignited. Jealousy is only one of the potential conflicts in post-dissolutional friendships. Other issues such as low commitment and loss of interest in the relationship can lead to potential challenges that make post-dissolutional friendship similar romantic relationships but distinct from friendships. Rules in the relationship must be refined, some romantic rules may be removed while friendship rules may be added, and hence post-dissolutional friendships can be studied from the rules perspective.

\section{The Rules Perspective}

Many studies suggest that relationships follow a negotiated set of rules (Argyle et al., 1979; Argyle \& Henderson, 1984, 1985; Cushman \& Whiting, 1972). According to Argyle and colleagues (1979), rules coordinate the behavior of individual members in 
relation to dyad goals and conventions. Rules regulate the communicative process within a relationship and make interactions meaningful. Human actions are largely dependent on a consensus of rules (Cushman, 1977). Additionally, rules are specific to the relationship in which individuals are engaged.

Shimanoff (1980) defines rules as a "followable prescription that indicates what behavior is obligated, preferred, or prohibited in certain contexts" (p. 39). West (2006) suggests that the reason that relational partners conform to rules is that rules provide "reinforcements such as conflict reduction, reducing communication costs and interference, provisions of external rewards, increasing the value similarity between dyad members, and ensuring task performance" (p. 16). West (2006) goes on to explain that rules are related to cost-reward ratios. The higher the reward, the better the ratio and the more cohesion in the relationship.

Just as relationships are always changing, so, too, may the set of rules. A rule may become inappropriate for a particular situation and must be altered to fit the changing nature of the relationship. By the same token, however, rules may also be broken. A rule may be broken by misapplication of a rule, a mistake of the terms of a rule, or the ignoring of the rule altogether. The breaking of rules may have a negative consequencejust as a violation of a rule in a board game may result in dissolution of the game, so too may a relationship terminate (Argyle $\&$ Henderson, 1985). The consequence of a broken rule could be as small as a disagreement in the relationship or as large as grounds for termination. For example, if the rule "partners should be faithful to one another" is broken, the disruption may cause the ending of the relationship completely. In a study of 
romantic relationship break-ups, Baxter (1986) found that 16\% of participants reported ending a relationship because of failure to follow the rule to maintain loyalty/fidelity.

Argyle and Henderson (1985) discovered several key findings when observing rules in personal relationships. They discovered that all personal relationships were structured by strongly endorsed rules and there was a general consensus of rules among the members. Two sets of rules were observed across both romantic relationships and friendships: maintenance rules and intimacy-reward rules (often referred to as reward rules). Maintenance rules are behaviors both intentionally and unintentionally performed to uphold a relationship, and include but is not limited to regulating time talking with each other, respecting privacy, volunteering help, avoiding public criticism. Maintenance rules operate to keep the relationship together by mitigating possible sources of conflict and friction. Intimacy-reward rules are needed to preserve the presence of rewards and minimize the costs for relational partners. Intimacy-reward rules stipulate that partners should love, provide support, comfort, and show affection for each other in both romantic and friendship relationships. Argyle and Henderson (1984) assert that, consistent with social exchange theory, people tend to stay in relationships where the reward-cost ratio is favorable.

To best understand how the rules perspective explains behaviors in postdissolutional friendships, rules present in both romantic relationships and friendships need further explanation. These rules are summarized in the sections that follow.

\section{Rules in Romantic Relationships}

While friendship may be an important part of a romantic relationship, Baxter et al. (1997) suggest that our expectations of lovers are different than our expectations of 
friends. Romantic partners are expected to invest more time in the relationship, attend more to their partners, be more committed and supportive, and to have more desirable traits than friends. Unfortunately, relatively few studies have focused on the investigation of rules within romantic relationships and a comprehensive list of rules within romantic relationships does not exist. However, Jones and Gallois (1989) sought to examine communication rules within public and private conflicts in marriage. They found that several rules regulated how spouses communicated: partners should (a) be considerate, (b) be rational, (c) be specific, (d) try to resolve conflict, and (e) maintain positivity in interactions. Regrettably, Jones and Gallois (1989) did not address which rules and expectations exist outside of conflict situations.

One way to determine the presence of a rule is to look at negative consequences as a result of a broken rule. In her 1986 study, Baxter used the rules perspective to describe broken rules in break-up accounts. Respondents answered questions about why a specific, past romantic relationship was terminated. The answers were analyzed and produced eight different romantic relationship rules that had been broken. The most frequently reported reason for a break-up was Autonomy (individuals in a romantic relationship should acknowledge that they have identities and lives beyond the relationship). The second most frequent cause was Similarity Display (individuals in the dyad should express similar attitudes, beliefs, values, and interests). The lack of Supportiveness (partners should enhance one another's self-work and self-esteem) was the third most frequent drive for the break-up. The fourth most cited motive for a breakup was Openness (partners should be open, genuine, and authentic with one another). Failure to maintain Loyalty/Fidelity (remaining faithful to one another) was the next most 
frequent reason for termination. The lack of Shared Time (partners should share a substantial amount of time with each other) was also attributed for the break-up. The seventh most reported motivation for a break-up was Equity (parties should reap rewards commensurate with their investments, relative to the other party). The final rule associated with a break-up of a romantic relationship was Romance (dating partners should experience a mysterious and inexplicable "magic" when in each other's presence). Baxter (1986) contends that these eight reasons are a guide to expectations and behavior and are thus rules of romantic relationships.

In an additional study conducted by Argyle and Henderson (1985), married and divorced dyads were studied. The divorced couples were involved in a post-dissolutional relationship. Maintenance rules were applied equally in both married and postdissolutional relationships. However, the difference between the frequencies of application of rules was in intimacy-reward rules. The married women cited applying more intimacy-reward rules than did the divorced women. Additionally, the divorcees reported fewer intimacy-reward rules being applied in the year leading up to the break-up of the marriage. The divorced women were still applying maintenance rules in their relationship but did not also endorse intimacy-reward rules (Argyle \& Henderson, 1985). This suggests that the decline in the relationship may have caused fewer intimacy-reward in the romantic relationship. As the rewards decreased the costs increased and as the relationship shifted so too did the application of rules within the dyad.

Just as a post-dissolutional friendship must change status from romantic relationship to friendship, so too must the rules. The platonic friendship rules present in 
post-dissolutional friendship rules must be examined to differentiate them from romantic rules.

\section{Rules in Friendship}

Argyle and Henderson (1984) sought to determine what rules were at play within platonic friendships. They conducted a series of studies that designed to identify rules present within friendship relationships. The studies strove to establish a general set of rules in friendships; understand the different rules in friendships across cultures; examine the differences in rule keeping between friendships that were current or lapsed; and to explore the impact that rule breaking may have within the dissolution of friendship.

In their first study, Argyle and Henderson (1984) hypothesized that friendships follow an informal set of rules. Using pilot interviews, they generated a list of informal rules that were relevant to different personal relationships. These interviews resulted in a list of 33 rules that were common to most types of personal relationships and ten rules specific to friendships. Argyle and Henderson then asked participants to rate the importance of the rules in friendship on a 9-point Likert-type scale ranging from high to low endorsement. Out of the 43 total rules, 21 received high endorsements. For a complete list of rules that received high endorsement, refer to Appendix A.

In their second study, Argyle and Henderson (1984) replicated their findings across three other cultures: Italy, Japan, and China. Four rules received high endorsement in all four cultures. These rules were that interaction partners: (a) should respect each other's privacy, (b) should trust and confide in one another, (c) should volunteer help in time of need, and (d) should not be jealous or critical of other's relationships. This suggests that there is some consensus among rules within friendships across cultures. 
Their next study predicted that lapsed friendships would report fewer kept rules (during the relationship) than continuing friendships. In this study, lapsed friendship referred to friendship that was once strong but is no longer particularly strong. Argyle and Henderson (1984) found that 23 out of 27 rules were kept significantly less in lapsed friendships than in current ones.

In their fourth study, Argyle and Henderson (1984) found that the breaking of several rules was estimated as having been moderately to very important in the causing of the break-up of a friendship. These rules are listed in Appendix B.

When Argyle and Henderson (1984) synthesized their results across the four studies, six rules were considered to be especially important within friendships. These six rules were highly endorsed, were able to distinguish between continuing friendship and lapsed ones; distinguish between high and low quality friendships; and when broken, these rules were found to contribute to the dissolution of a friendship. The most important friendship rules were: (a) standing up for the other in his/her absence; (b) sharing news of success with him/her; (c) showing emotional support; (d) trusting and confiding in each other; (e) volunteering help in time of need; and (f) striving to make him or her happy. Additionally, Argyle and Henderson (1984) found four broad categories of rules present in friendships:

1. Rules that signal or help sustain intimacy

2. Rules governing the exchange of rewards

3. Rules that regulate potential conflict within the relationship

4. Rules that regulate potential conflict as a result of interactions with third parties 
Schneider and Kenny (2000) created a similar study to determine how people applied friendship rules differently with platonic cross-sex friends and ex-romantic partners. The authors used the six rules that were highly endorsed in Argyle and Henderson's (1984) study to examine higher versus lower quality relationships: stand up for the other in his/her absence, share news of success, show emotional support, trust and confide in each other, volunteer help in time of need, and strive to make each other happy. The results indicated a noteworthy difference between the two relationship types. Not surprisingly, people applied those six rules of friendships more often with their platonic friend than with their former romantic partner. By this standard, the authors argued that ex-romantic partner friendships could be characterized as lower quality than platonic relationships. The platonic partnerships offered more benefits than their counterparts and ex-romantic partnerships were thought of as less close and more casual. However, people had more desire to be romantically involved with their former partner than their platonic friends. Evidence suggests that lingering romantic desires may not be the only reason former dating partners decide to remain friends. However, those who have experienced strong friendship during or before their romantic relationship may be able to establish a platonic friendship more easily (Schneider \& Kenny, 2000).

Overall, Argyle and Henderson (1984) suggest that rules play a role in the development of a friendship and that the rules must be adhered to in order for the friendship to continue. The adherence to these rules allows the relationship to flourish and grow. If these rules are not adhered to, it is likely that the friendship will be terminated. While the focus of Argyle and Henderson's (1984) study was on friendship relationships, it is to be expected that rules that govern friendships may overlap with 
those that dictate romantic relationships considering that many consider friendship to be an important component of romantic relationships.

\section{Rules in Post-Dissolutional Friendships}

Prior to the break-up, couples have a set of relational rules. But what happens when formerly romantic partners decide to become friends? What set of rules do they then follow? Now, the formerly dating partners may find themselves facing a partially obsolete set of rules. In order for the relationship to continue, the dyad must begin to act differently and perform under a new set of relational rules. Romantic relationship rules have guided the dyads past actions for acceptable behavior. Now that the dyad has chosen to continue their relationship in the mode of a friendship, a new set of rules must be put into place, but what are those rules? Little research has been done on the prevalence of rules in post-dissolutional friendship. These non-traditional relationships do not have a specific mold to follow and therefore have to negotiate a new set of relational rules for the dyad to follow.

While some rules of the romantic relationship or friendship may be employed in post-dissolutional friendships, others may become obsolete. It is important to know to what extent post-dissolutional friendships resemble platonic friendships and romantic relationships. In order to determine the types of rules being employed in postdissolutional friendships the following research questions must be asked:

$\mathrm{RQ}_{1}$ : What romantic relationship rules are important in post-dissolutional friendships?

$\mathrm{RQ}_{2}$ : What friendship rules are important in post-dissolutional friendships? 
It is likely that post-dissolutional relationships follow rules that are neither romantic nor friendship rules. Rules in post-dissolutional friendships that are rated as both important and are followed by partners may be unique to only this type of relationship. To create a list of new rules endorsed in post-dissolutional friendships the final research question needs to be asked:

$\mathrm{RQ}_{3}$ : What rules, not already present in friendship and romantic relationship rules, exist in post-dissolutional friendships?

Post-dissolutional friendships must be governed by a set of rules in order for them to remain intact. Because the romantic nature of the relationship is over, it is not likely that intimacy-reward rules would be as important, or in play at all. However, this puts more stress on maintenance rules to keep the relationship from lapsing. Both partners must adhere to maintenance rules. Maintenance rules keep the relationship together by limiting possible sources of friction. From this, I propose the following hypotheses:

$\mathrm{H}_{1}$ : Participants will rate maintenance rules as more important than intimacyreward rules in post-dissolutional friendships.

$\mathrm{H}_{2}$ : Participants will report that their partners follow maintenance rules more often than intimacy-reward rules.

Just as traditional relationships vary in quality, so too do post-dissolutional friendships. Research suggests that the quality of relationships is related to how well relational rules are followed. Therefore, the extent to which a respondent's partner follows rules that the respondent deems as important is related to relationship quality. From this understanding a final hypothesis can be drawn: 
$\mathrm{H}_{3}$ : The quality of post-dissolutional friendships will be positively correlated to how well relational partners are perceived to adhere to rules that participants deem important. 


\section{CHAPTER III}

\section{METHOD}

The previous chapter summarized the research relevant to post-dissolutional friendships and the rules perspective. The current chapter discusses participants, procedures, and data analysis of the current study.

\section{Participants}

Participants were recruited from communication courses at a large Midwestern public university in the spring semester of 2015. Participants were drawn from the School of Communication research pool. Students were offered no credit, credit, or extra credit for participation in the study. Additionally, Facebook was used to recruit participants for the study. A call for participation in the study was posted on the author's Facebook status. A total of 179 individuals participated in the survey ( 35 males, 116 female, 28 no response). The ages for participants ranged from 18 years to 63 years with a mean of 23 years $(S D=6.15)$. The mean length of the romantic portion of the relationship prior to termination was 1 year and 7 months $(S D=18.39$ months $)$. The mean range of times since the romantic relationship dissolved was 3 years and 4 months $(S D=53.29$ months $)$. The sample consisted of four African Americans, five Asians, 125 Caucasians, five Latino/as, ten individuals who reported multiracial backgrounds, and 30 participants who did not want to disclose their ethnicity. (See Appendix C for complete survey 
instrument). In the sample, $62.6 \%$ were friends prior to the romantic portion of their relationships. There was no difference in solidarity scores for those who were and were not friends prior to the romantic relationship. This is not surprising, since the sample consisted of individuals who successfully transitioned from romance into friendship. A total of $45.8 \%$ of participants were currently in a romantic relationship with someone other than the friend they reported on the survey. When answering how often participants communicate with their former partner, $9 \%$ said at least once a day, $19 \%$ said a few times a week, $15 \%$ said once a week, $31 \%$ said a few times a month, and $26 \%$ said once a month.

\section{Procedure}

Participants were asked to complete a survey regarding their current postdissolutional friendship. In the first section of the survey, participants were given a set of rules that may be present in their post-dissolutional friendship. They were asked to rate how important the rules were to their current post-dissolutional friendship on a 7-point scale from (1) not important to (7) very important. This set of 22 questions was developed using Argyle and Henderson's (1984) list of friendship rules as well as Baxter's (1986) and Jones and Gallois' (1989) romantic relationship rules (see Table 1 for complete list). Out of the 22 rules, 13 rules were taken from Argyle and Henderson's list of friendship rules, three rules were taken from Baxter's romantic relationship rules, and two were taken from Jones and Gallois' romantic relationship rules. Four rules appeared in several of the different lists. Three rules appeared in both Argyle and Henderson and Baxter's list of rules and one rule appeared on all three lists. Several existing rules from romantic relationship rules and friendship rule lists were excluded 
because of the unique nature of post-dissolutional friendships. For example, rules that were strictly about sexual intimacy in romantic relationships were left out because that component of the relationship was now irrelevant. 
Table 1

Rules of Post-Dissolutional friendships Included in the Current Survey

\begin{tabular}{|c|c|c|c|}
\hline Rule & $\begin{array}{c}\text { Friendship/ } \\
\text { Romantic }\end{array}$ & $\begin{array}{l}\text { Rule } \\
\text { Type }\end{array}$ & Source * \\
\hline Should disclose feelings and personal problems & Friendship & IR & $\mathrm{AH}$ \\
\hline Should ask for personal advice & Friendship & IR & $\mathrm{AH}$ \\
\hline Should not criticize in public & Friendship & M & $\mathrm{AH}$ \\
\hline Should stand up for in absence & Friendship & M & $\mathrm{AH}$ \\
\hline Should not discuss what is said in confidence & Friendship & M & $\mathrm{AH}$ \\
\hline Should not indulge in sexual activity & Friendship & IR & $\mathrm{AH}$ \\
\hline Seek to repay debt & Friendship & IR & $\mathrm{AH} / \mathrm{B}$ \\
\hline Seek to repay favor & Friendship & IR & $\mathrm{AH} / \mathrm{B}$ \\
\hline Should share new of success & Friendship & IR & $\mathrm{AH}$ \\
\hline Should respect privacy & Friendship & M & $\mathrm{AH}$ \\
\hline Should be emotionally supportive & Friendship & IR & $\mathrm{AH} / \mathrm{B} / \mathrm{JG}$ \\
\hline Should not nag & Friendship & M & $\mathrm{AH}$ \\
\hline Should be tolerant of each other's friends & Friendship & M & $\mathrm{AH}$ \\
\hline Should trust and confide in each other & Friendship & IR & $\mathrm{AH} / \mathrm{B}$ \\
\hline Should volunteer help & Friendship & M & $\mathrm{AH}$ \\
\hline Should not be jealous of other's relationships & Friendship & M & $\mathrm{AH}$ \\
\hline Should strive to make other happy & Friendship & IR & $\mathrm{AH}$ \\
\hline Should try to resolve conflict & Romantic & M & JG \\
\hline Should maintain positivity in interactions & Romantic & M & JG \\
\hline $\begin{array}{l}\text { Should be tolerant of each other's romantic } \\
\text { relationships }\end{array}$ & Friendship & M & B \\
\hline Should not discuss sexual encounters with other & Romantic & IR & B \\
\hline Should spend time talking with the other & Romantic & M & B \\
\hline
\end{tabular}


The second section of the survey asked individuals to identify any rules unique to their own post-dissolutional friendship that were not listed in the first set of rules. This section asked participants to identify and describe up to three different rules that they found to be important. After listing the rule, they were asked to rate the importance of the rule to their post-dissolutional friendship on the same 7-point scale from (1) not important to (7) very important.

In the next section, participants were given the same set of 22 rules and were asked to indicate to what extent they believed that their post-dissolutional friend adhered to each of the rules. Participants rated this on a scale from (1) never to (5) always. In the subsequent section, participants rated the closeness of their postdissolutional friendship using the Interpersonal Solidarity Scale. The interpersonal solidarity scale tests feelings of closeness between people that develop as a result of shared sentiments and similarities. Items included questions about trust, liking, and selfdisclosure (e.g., I trust this person completely, I like this person much more than most people I know). The scale was developed by Wheeless (1976) and has shown spilt-half reliabilities of .96 (Wheeless, 1976) and .94 (Wheeless, Wheeless, \& Baus, 1984). Participants rated 20 items on a 7-point Likert-type scale from (1) strongly disagree to (7) strongly agree. The interpersonal solidarity scale exhibited alpha reliability of .93 in this study. The final section of the survey asked participants to fill out demographic information including: age, sex, ethnicity as well as the age and sex of the participant's post-dissolutional friendship partner. 


\section{Data Analysis}

To answer research question one, which romantic relationship rules are deemed as important in post-dissolutional friendships, a criterion for importance was first developed. The importance for post-dissolutional rules was determined on a 7-point scale. If the mean score was five or higher, the rule was be considered important to the postdissolutional friendship. The second research question was answered in the same manner as the first. A mean score for the importance of friendship rules in their post-dissolutional friendships can be found using the same criterion (i.e., a rating of five or higher on the 7point scale).

The final research question was answered by completing a content analysis of open-ended responses on the survey. The question was: "You have just responded to a list of rules that may potentially apply in your post-dissolutional relationship. It is possible that you find rules not listed above to be important. If there are any rules that you find important, briefly describe them below. Please identify up to three rules." A content analysis was be performed on the open-ended questions in order to determine if any of the rules participants listed were not on the previous friendship and romantic relationship lists and thus distinctive to post-dissolutional friendships. A list of new postdissolutional friendship rules was then compiled. Additionally, participants rated the importance of each of their own rules on a 7-point scale. Using the same criterion as in the first two research questions, if a participant rated the rule as five or higher on the scale, the rule was considered to be important to their post-dissolutional friendship.

The survey included 12 items that were characterized as maintenance rules according to Argyle and Henderson's (1985) findings. To verify the importance of 
maintenance rules, an average score for all maintenance items was compiled. A mean score for each individual was computed to define the average importance of maintenance rules as a whole. Then, an average of the importance of maintenance rules for all participants was computed. The same process was done for the 10 intimacy-reward rules. After the two mean scores for maintenance and intimacy-reward rules were calculated, a paired-samples $t$-test was used to test the first hypothesis.

The second hypothesis was tested in a manner similar to the first hypothesis. Once again, a mean score for adherence to maintenance rules was computed for each individual as well for all participants. Then, the following of the intimacy-reward rules mean score was created. After the two mean scores for the following of maintenance and intimacyreward rules were calculated, a paired samples $t$-test was run to test hypothesis two.

The third hypothesis used a correlation to assess the relationship between closeness of the post-dissolutional friendship and the extent to which partners follow post-dissolutional friendship rules deemed to be important. The adherence to important rules was calculated in two ways. First, based on the rules deemed important by the entire sample in $\mathrm{RQ}_{1}$ and $\mathrm{RQ}_{2}$, an average score reflecting how often each participant's partner adheres to those rules was computed. Second, an index of adherence to important rules was calculated for each participant by (a) multiplying the importance rating for each rule by the rating of partner's adherence to that rule, and then (b) averaging these product terms across all 22 rules for each participant. Higher scores represent a greater degree of participants perceiving that the partner adheres to rules deemed important 


\section{CHAPTER IV}

\section{RESULTS}

The previous chapter explained the research methodology. The current chapter presents the results of the study.

\section{Research Questions}

In order to answer research question one, the mean score of the importance of each romantic rule was calculated. When the mean score was five or higher on a 7-point scale, the rule was considered to be very important to the post-dissolutional relationship. Of the four romantic relationship rules in the survey instrument, two were deemed to be very important in the post-dissolutional friendship with mean scores of 5.71 and 5.53 . The other two romantic rules still received moderately high importance scores because they were above the scale mid-point with means of 4.91 and 4.61 (see Table 2).

To answer research question two, mean importance scores were calculated for each friendship rule. Of the 18 friendship rules, 12 were deemed as very important to participants with mean scores ranging from 5.0 to 6.03. Only four of the scores fell below the scale mid-point of 4.0. See Table 2 for full mean score results. 
Table 2

Rules Deemed to be Important in Post-Dissolutional Friendships

\begin{tabular}{|c|c|c|c|}
\hline Rule & $\begin{array}{l}\text { Friendship/ } \\
\text { Romantic }\end{array}$ & $M$ & $S D$ \\
\hline Should disclose feelings and personal problems & Friendship & 4.26 & 1.74 \\
\hline Should ask for personal advice & Friendship & 4.13 & 1.64 \\
\hline Should not criticize in public & Friendship & 5.67 & 1.69 \\
\hline Should stand up for in absence & Friendship & 5.25 & 1.61 \\
\hline Should not discuss what is said in confidence & Friendship & 5.90 & 1.45 \\
\hline Should not indulge in sexual activity & Friendship & 5.32 & 2.00 \\
\hline Seek to repay debt & Friendship & 3.53 & 1.99 \\
\hline Seek to repay favor & Friendship & 3.12 & 1.77 \\
\hline Should share new of success & Friendship & 4.93 & 1.73 \\
\hline Should respect privacy & Friendship & 6.03 & 1.28 \\
\hline Should be emotionally supportive & Friendship & 5.31 & 1.69 \\
\hline Should not nag & Friendship & 5.27 & 1.60 \\
\hline Should be tolerant of other's friends & Friendship & 5.00 & 1.68 \\
\hline Should trust and confide in each other & Friendship & 4.81 & 1.77 \\
\hline Should volunteer help & Friendship & 5.12 & 1.47 \\
\hline Should not be jealous of other's relationships & Friendship & 5.62 & 1.43 \\
\hline Should strive to make other happy & Friendship & 5.00 & 1.50 \\
\hline Should try to resolve conflict & Romantic & 5.29 & 1.39 \\
\hline Should maintain positivity in interactions & Romantic & 5.53 & 1.33 \\
\hline $\begin{array}{l}\text { Should be tolerant of each other's romantic } \\
\text { relationships }\end{array}$ & Friendship & 5.71 & 1.33 \\
\hline Should not discuss sexual encounters with other & Romantic & 4.91 & 2.01 \\
\hline Should spend time talking with the other & Romantic & 4.61 & 1.76 \\
\hline
\end{tabular}

Note: Rules in bold font were deemed very important to post-dissolutional friendship. 
To answer the final research question, a content analysis of open-ended responses on the survey was completed. This was done in order to determine if post-dissolutional partners follow any additional rules not included in the structured list contained in the survey. Participants suggested a total of 101 new rules: however, $71.29 \%$ of the rules described already fit the definition of existing friendship or romantic relationship rules. Fifty-two of the rules listed were friendship rules: 46 of which were the same rules as listed in the survey instrument (e.g., many participants wrote about being tolerant of romantic relationships, which was already a friendship rule), 6 were friendship rules mentioned in other parts of friendship rule literature but not included in the survey (e.g., addressing partners by their first name). Twenty of the rules listed were romantic relationship rules, all of which fit the definition of romantic rules in the survey. The content analysis revealed 10 new post-dissolutional relationship rules, eight of which were identified by more than one participant. The participants also rated the importance of these distinctive rules on a 7-point scale. All of the rules received high importance ratings and thus were considered to be very important to post-dissolutional friendship. These rules fall under the categories of both maintenance and intimacy-reward rules. See Table 3 for a complete list. 
Table 3

Rules Distinctly Important to Post-Dissolutional Friendships

\begin{tabular}{lccc}
\hline Rule & $\begin{array}{c}\text { Intimacy-Reward/ } \\
\text { Maintenance }\end{array}$ & $\begin{array}{c}\text { Mean } \\
\text { Importance }\end{array}$ & Frequency \\
\hline Should not talk about romantic portion of relationship. & Both & 6.00 & 5 \\
Should give space to PDF partner. & Maintenance & 7.00 & 3 \\
Should respect partners' request to end friendship. & Maintenance & 7.00 & 2 \\
Should not discuss lingering romantic feelings. & Both & 7.00 & 4 \\
Should not bother PDF partner on social media. & Maintenance & 7.00 & 2 \\
Should not rehash arguments had during dating portion of & Maintenance & 6.33 & 6 \\
$\quad$ & & & \\
relationship. & Maintenance & 7.00 & 1 \\
Should not be romantically involved with friends of PDF partner. & Both & 5.67 & 3 \\
Should disclose the nature of the PDF to social network. & Intimacy-Reward & 7.00 & 1 \\
Should interact with PDF partner's family. & Maintenance & 5.50 & 2 \\
Should not discuss PDF with current romantic partners. & &
\end{tabular}




\section{Hypotheses}

In order to test hypothesis one, an average score of importance of maintenance rules and an average score of importance for intimacy-reward rules were computed across participants. A paired-samples $t$-test was conducted to compare rated importance of maintenance rules with rated importance of intimacy-reward rules. There was a significant difference such that participants found maintenance rules $(M=6.55, S D=$ 0.86 ) to be more important to their post-dissolutional friendships than intimacy-reward rules $(M=4.53, S D=1.03, t[178]=34.53, p<.001, r=.93)$. Thus the first hypothesis was supported.

The second hypothesis was tested in a manner similar to the first. Mean scores for how often participants' partners were perceived to follow maintenance rules and how often participants' partners were perceived to follow intimacy-reward rules were computed. A paired samples $t$-test was conducted to compare the following of maintenance rules and intimacy-reward rules. There was a significant difference in the scores such that maintenance rules $(M=3.73, S D=0.73)$ were perceived to be followed significantly more frequently than intimacy reward rules $(M=3.40, S D=0.78, t[153]=$ 7.30, $p<001, r=.51$ ) This finding supported hypothesis two.

The final hypothesis was tested using a correlation to assess the relationship between participants' interpersonal solidarity score and the following of important rules. Two different measures of rule following were computed to test this hypothesis. First, based on the rules deemed important by the entire sample in $\mathrm{RQ}_{1}$ and $\mathrm{RQ}_{2}$, an average score reflecting how often each participant's partner follows those rules was computed (index 1). Second, an index of the following of important rules was calculated for each 
participant by (a) multiplying the importance rating for each rule by the rating of partner's following of that rule, and then (b) averaging these product terms across all 22 rules for each participant (index 2). The two index measures were substantially correlated with each other $(r=.89, p<.001)$. The correlation for index 1 and interpersonal solidarity was $r(151)=.43, p<.001$. The correlation between index 2 and interpersonal solidarity was $r(151)=.54, p<.001$. This affirms that the quality of post-dissolutional friendships was positively correlated to how well relational partners were perceived to adhere to rules that participants deemed important. 
CHAPTER V

DISCUSSION

This chapter will discuss the results. Following the review of all research questions and hypotheses, implications, limitations of the study, and areas for future research are examined.

\section{Summary of Findings}

\section{RQ1: Important Romantic Relationship Rules in PDFs}

Research question one asked which romantic relationship rules were important in post-dissolutional relationships. Participants rated two of the four romantic relationship rules as highly important to post-dissolutional relationships. When returning to the literature, this answer, primarily, follows what previous scholars have discussed. Take for example, the rule, "should try to resolve conflict" which was deemed to be very important to the post-dissolutional friendship. Friendship requires negotiation and conflict tears apart relationships. Koenig Kellas et al. (2008) articulated that arguments were associated with negative quality of a relationship; therefore, it is understandable that resolving conflict received such a high mean score. If a partner introduces too many conflicts into a relationship, it is likely that the partner will find ways to reduce the cost of these conflicts (Banks et al., 1987). If too many conflicts arise in a relationship and 
remain unresolved, the quality of the relationship will suffer and could eventually lead to termination of the friendship.

The second romantic relationship rule that received high importance in postdissolutional friendships was "should maintain positivity in interactions." This rule appears to be more of a universal relationship rule, not just unique to romantic attachments. According to Jones and Gallois (1989), this rule was about providing more rewards in the relationship than costs in order to maintain the relationship during conflict situations. To best understand this, we must relate this back to social exchange framework - the more rewards individuals receive from a former romantic partner, the more likely they are to maintain that relationship. In this case, positivity in interactions between partners would be a reward and negativity in interactions would be considered a cost. The higher the reward in a relationship and lower costs, the more satisfied the members of the relationships are (Busboom et al., 2002). Thus, participants' rating this rule as very important to their post-dissolutional friendship is consistent with past research.

There were two romantic relationship rules that were not rated as highly important to post-dissolutional friendships but received relatively high mean scores and should be discussed in detail. The first of these rules was "should not discuss sexual encounters with the other." This rule had a mean score of 4.91 but did not quite fulfill the criterion for highly important rule. However, it should be noted that $58.1 \%$ of participants rated this rule as highly important (i.e., 5 or higher on the 7-point scale). This rule dictated that partners should not discuss sexual encounters with members outside of the postdissolutional friendship with the post-dissolutional friendship partner. For some 
participants, discussing sexual encounters was acceptable. Sexual encounters with others outside of the post-dissolutional friendship implies that one or more of the partners is moving on to a new romantic relationship. Because the nature of the relationship has turned into a friendship, sexual encounters with others can be discussed again. Becoming close friends is associated with positive redefinition of the relationships (Koenig Kellas et al., 2008). However, some individuals may not want to discuss sexual encounters because of feelings of jealousy. Schneider and Kenny (2000) found that some individuals cite wanting to become romantically involved with an ex-partner again as a reason for maintaining a friendship. These individuals still harboring romantic feelings may be upset by the ex-partner's new romantic relationship. For these types of relational partners, discussing sexual encounters with each other may not be possible without negative redefinition of the post-dissolutional friendship (Koenig Kellas et al., 2008). This rule illustrates that each post-dissolutional relationship is distinct and different rules may apply in some relationships but not others.

The second romantic rule that was moderately important to post-dissolutional friendships was, "should spend time talking with the other." Romantic relationship and friendship partners have different needs in terms of time spent talking to each other. Baxter and colleagues (1997) assert that individuals expect their romantic partners to invest more time and attend to their partner than friends. However, post-dissolutional partners must spend time talking with each other in order for there to be a relationship. If post-dissolutional friendship partners end the romantic relationship but do not continue to communicate, it is just an amicable break-up. 


\section{RQ2: Important Friendship Rules in PDFs}

The second research question asked, what friendship rules are important in postdissolutional friendships? Of the 18 friendship rules in the survey instrument, 12 received a mean score of five or above and were considered to be highly important to the postdissolutional friendship. Primarily, these rules helped to either mitigate the possibility of conflict or to maintain friendship boundaries in the post-dissolutional friendship.

The rules that helped to mitigate the possibility of conflict were (in order of highest mean score to lowest): "should not discuss what is said in confidence," "should be tolerant of each other's romantic relationships," "should not criticize the other person publically," "should not be jealous or critical of other's relationships," "should not nag the other person," "should stand up for the other person in their absence," and "should be tolerant of each other's friends."

It is very possible that these rules could also be rated highly important to romantic relationships because they reduced sources of friction in order to keep rewards high and costs low in the relationships. Schneider and Kenny (2000) explain that rules that mitigate conflict were applied more frequently in post-dissolutional friendships than in strictly platonic friendships with no romantic history. These seven rules serve to prevent jealousy-provoked interactions and maintain quality of friendship. Conflict has been found to lead to poor quality of post-dissolutional relationships (Graham, 1997). Conflict leads to arguments, uncomfortable interaction, jealousy-provoked interactions, and harassment, all of which also lead to the negative redefinition of post-dissolutional relationship (Koenig Kellas et al., 2008). These rules are established in order to quell conflict between the post-dissolutional friendship partners. 
There were five friendship rules that helped to define and maintain friendship boundaries. They were (in order of highest mean score to lowest): "should respect the other's privacy," "should not indulge in sexual activity with the other person," "should be emotionally supportive," "should volunteer help in time of need," and "should strive to make the other happy while in their company."

These five rules served to establish boundaries between the formerly romantic relationship and current, platonic friendship. The history of romance between the partners could make the transition to friendship difficult because the potential for renewed romantic desire is high (Schneider \& Kenny, 2000). These rules serve to keep romantic feelings in the past by making the relationship completely platonic. These rules also emphasize the need to be caring and supportive of the partner even without romantic desire or sexual encounters. Schneider and Kenny (2000) found that if friendship-specific rules are not kept, it is likely that the friendship quality may suffer and could lead to complete dissolution. The high importance rating of these five rules confirms Schneider and Kenny's findings and further recognizes the importance of friendship rules in the maintenance of post-dissolutional friendships.

\section{RQ3: Rules Distinctly Important to PDFs}

The final research question asked what rules, not already present in friendship and romantic relationship rules, exist in post-dissolutional friendships? After completing a content analysis of open-ended research questions, a set of ten rules specific to postdissolutional relationships was identified. The list included both maintenance and intimacy-reward rules; however, many of these rules have characteristics of both 
maintenance and intimacy-reward rules perhaps due to the nature of post-dissolutional relationships.

The first rule was "should not talk about romantic portion of the relationship." This rule can be classified as a maintenance rule because it serves to keep the relationship together by mitigating the sources of friction when discussing the romantic portion of the relationship. This rule also has characteristics of an intimacy-reward rule because it serves to keep affectionate communication and intimacy in the past. It is likely that members of post-dissolutional relationships follow this rule because they want to focus on the friendship nature of the relationship rather than past romantic occurrences. It is also possible that bringing up the romantic portion of the relationship may stir up feelings of hope to renew the relationship and thus the rule must be followed. According to Lannutti and Cameron (2002), hope to renew the romantic relationship was negatively associated with satisfaction with the post-dissolutional friendship. This rules suggests that it is best to leave the past in the past.

The second post-dissolutional friendship rule was a maintenance rule and stated that post-dissolutional friends "should give space to post-dissolutional friendship partner." Unlike romantic relationships, where time together is more highly desired, postdissolutional partners need space. This is a maintenance rule because it regulates time talking to each other. This rule received a mean score of 7.0 and was brought up by three of the participants. On the other side of the coin, in romantic relationships, one of the most cited reasons for a break-up was autonomy (Baxter, 1986). Post-dissolutional partners need to acknowledge that both individuals have lives outside of the friendship. 
This rule further defines the boundaries of post-dissolutional friendship from romantic relationship.

The third rule postulated that partners "should respect partners' request to end friendship." This rule also falls under maintenance because it regulates time spent together, if at all. Because of the delicate nature of the post-dissolutional friendship, the request to end the relationship altogether must be respected. An abundance of emotions are experienced in post-dissolutional relationships and it is important to recognize that not all of these emotions are positive. If the emotional toll of being friends with a former romantic partner becomes too high, the relationship may become overwhelming. Additionally individuals must be given the opportunity to move on. It is also possible that a new romantic partner may pressure an individual to end their post-dissolutional friendship in order to focus on their current romantic relationship. On the reverse side of this, some individuals will not begin a new romance while they are still friends with an ex. One of the barriers to post-dissolutional relationships is the opportunity to take another romantic partner (Busboom et al., 2002). If a partner requests to end the relationship due to feelings for another person, this request must be supported. "Should not discuss lingering romantic feelings" was the fourth rule listed by participants. This was the second most cited rule by participants answering the openended question and received the highest mean score of 7.0. This rule is an intimacyreward rule because it deals with the display of affection for each other. It also falls under the category of maintenance rule because it attempts to keep the relationship together by moderating sources of friction and maintaining friendship boundaries. Discussing lingering romantic feelings undermines the successful transition to friendship status. 
Unwanted displays of affection would likely cause conflict within the post-dissolutional relationship. It is not surprising that participants listed this as a rule. In Koenig Kellas et al.'s 2008 article, "lasting feelings" was a turning-point that indicated "holding on." If the post-dissolutional friendship is to be only a friendship, then romantic feelings need to be let go of to keep the post-dissolutional relationship intact. This rule is crucial to postdissolutional relationships.

Similar to rule two, the fifth rule also dealt with giving space, this time online. Rule five stated that partners "should not bother post-dissolutional friendship partner on social media." This is a maintenance rule because it deals with privacy management. This rule is relatively new to the post-dissolutional friendship arena because of the increasing popularity in social media. This rule further articulates that post-dissolutional friendships need space, even if it is in the virtual world.

The sixth rule is also a maintenance rule and states that partners "should not rehash arguments had during dating portion of the relationship." It is similar in nature to the first rule but is specifically related to reducing sources of friction between the partners. This rule encourages partners to move past the dating portion of the relationship and focus on matters in the present. Arguments may lead to negative quality of the relationship and as such, should not be brought up again (Koenig Kellas et al., 2008). If arguments are rehashed, a flood of negative emotions may devastate the friendship.

"Should not be romantically involved with friends of post-dissolutional friendship partner" was the seventh rule that participants cited. This is a maintenance rule that seeks to avoid conflict and establish boundaries in the relationship. It is very possible that partners would begin to experience jealousy if they were to date a friend of their post- 
dissolutional friendship partner. Partners may see this action as an act of betrayal and may feel hurt or jealous. This rule attempts to regulate the possibility of jealousyprovoked interactions that could reduce the quality of the relationship (Koenig Kellas et al., 2008). While this may not be the case for every dyad, some participants found the rule to be very important to their post-dissolutional friendships.

The eighth rule also deals with post-dissolutional friendship partners and their combined social network. Rule eight states that partners" "should disclose the nature of post-dissolutional friendship to their social network." This is an intimacy-reward rule because it attempts to show support for the relationship. It can also be a maintenance rule because it reduces sources of conflict; however, the conflict would be between the postdissolutional friendship partners and their social network. It is not surprising that partners would want to share their relationship status with their social network in order to garner support for their continued relationship. Lannutti and Cameron (2002) found that social networks had a profound impact on post-dissolutional relationships. Post-dissolutional relationships are especially open to criticism from outsiders who do not understand the relationship between partners. Open communication about the nature of the relationship with the social network hopefully allows for more support from outside sources.

The ninth rule is also an intimacy-reward rule and states that partners "should interact with the post-dissolutional friendship partners' family." This rule dictates that partners show emotional support for each other by being cordial with family members. It also received the highest mean score of 7.0, however, it was only suggested by one participant. This rule goes beyond just the social network of friends and into the familial realm. This rule stresses that post-dissolutional friendship partners provide care and 
comfort for each other by sharing in the lives of their post dissolutional friendship partners' families. This rule may especially important for divorced families. If children are a result of the previous romantic relationship, connection with former partners' family may become especially important. Divorced couples must learn how to work together to raise their children and this may be best achieved by relying on both families for support. A well functioning bi-nuclear family is crucial to the well being of children (Graham, 1997). By maintaining a positive relationship with family members of post-dissolutional friendship partners, the care of children may be more easily achieved. This rule is crucial for the care and comfort of post-dissolutional friendship partners.

The final post-dissolutional relationship rule guides that partners "should not discuss post-dissolutional friendship with current romantic partners." This maintenance rule also deals with privacy management but privacy for the post-dissolutional friendship partners together rather than separate. Unlike the eighth rule, where the social network was encouraged to be in the know about the relationship, this rule calls for silence. This is possibly done to quell the fears of the new partner about a flame of romance reigniting or to mitigate conflict within the new romantic relationship.

This list of post-dissolutional friendship rules is by no means exhaustive but it begins to describe the nuances of these types of relationships. While this list starts to define post-dissolutional friendships, it is important to remember that every postdissolutional friendship is distinct and has its own set of rules. These rules were specific to the set of participants in this study only. Increased research on post-dissolutional friendship rules would allow us to further generalize about rules present in these relationships. 


\section{H1: Importance of Maintenance and Intimacy-Reward Rules}

The first hypothesis predicted that participants would rate maintenance rules as more important than intimacy-reward rules in their post-dissolutional friendships. The first hypothesis was supported. This reaffirmed the absolute necessity of maintenance rules in post-dissolutional friendships. Maintenance rules keep the post-dissolutional relationship from lapsing. By following these rules, partners are mitigating possible sources of friction between the two and can uphold the newly formed friendship.

Out of the 12 maintenance rules, participants rated 11 rules as highly important. The maintenance rules that were found to be highly important in post dissolutional relationships (from highest mean score to lowest) were: "should respect other's privacy," "should not discuss that which is said in confidence with the other person," "should be tolerant of each other's romantic relationships," "should not criticize the other person publically," "should not be jealous or critical of other's relationships," "should maintain positivity in interactions," "should try to resolve conflict," "should not nag the other person," "should stand up for the other person in their absence," "should volunteer help in time of need," and "should be tolerant of other each other's friends."

To best understand these rules, they must be further separated into three categories of purpose: to reduce friction, to provide support, and to manage privacy in the post-dissolutional relationship. The first category, reduction of friction, sought to diminish sources of disagreement in the relationship by maintaining positivity in all interactions, not criticizing each other in public, not nagging the other person and trying to resolve conflict. These rules attempted to lower the costs of the relationship in order to improve relational quality. 
The second category, support, urged partners to be tolerant of each other's platonic friendships and romantic relationships, stand up for each other in absence, volunteer help in time of need, and to avoid being critical of relationships with people outside of the post-dissolutional friendship. These rules ensure that post-dissolutional friendship partners show social support for each other in order to keep the relationship intact.

The final category, privacy management, dictates that post-dissolutional friendship partners should respect each other's privacy and not discuss what is said to each other in confidence. These rules help build trust and respect within the friendship. These rules ensure that partners remain loyal towards each other even after the romantic relationship termination.

Not surprising, these results followed the same pattern that Argyle and Henderson's 1985 study did. In Argyle and Henderson's study, maintenance rules were applied more often than intimacy-reward rules in post-dissolutional relationships. The high rating of importance of 11 maintenance rules demonstrates how vital maintenance rules are to post-dissolutional relationships. Because of the volatile nature of postdissolutional friendship, behaviors that help maintain the structure of the friendship become especially important.

\section{H2: Following of Maintenance and Intimacy-Reward Rules}

The second hypothesis was also supported. Participants reported that their partners followed maintenance rules more often than intimacy-reward rules. Based on the results from hypothesis one, it is logical that partners would follow rules that their 
partners' deem to be important to keep the relational quality high. The following of maintenance rules helps to ensure that the post-dissolutional friendship will continue.

West (2006) articulates that participants' partners likely follow maintenance rules because "agreement to a given rule is reinforced by the function value to the relationship; that is, it's ability reduce cost and improve rewards" (p. 16). Maintenance rules define expectations for the partnership. If participants' partners violated maintenance rules, the cohesion of the relationship would likely suffer. These maintenance rules serve to make sense of partners' behavior and attempt to lessen damage on the relationship.

In hypothesis one, intimacy-reward rules were not found to be as important as maintenance rules in post-dissolutional friendships. As a result of this finding, it is logical that participants' partners did not follow these intimacy-reward rules as often as maintenance rules. Since post-dissolutional friendships are platonic, the need for intimacy-reward rules is not as high as in romantic relationships.

\section{H3: Rules and Solidarity}

The final hypothesis predicted that the quality of post-dissolutional friendships will be positively correlated to how well relational partners adhere to rules that participants deem important. A correlation test was run between perceived partner adherence to important rules and interpersonal solidarity. The interpersonal solidarity scale test was used because it encompasses trust, liking, and self-disclosure between members of the dyad. These factors were tested because liking for the ex-partner is a positive predictor of post-dissolutional friendship quality (Koenig Kellas et al., 2008). The extent to which participant partners followed rules that participants deemed as 
important was positively correlated to interpersonal solidarity and, thus, the final hypothesis was supported.

These findings echo and reaffirm Argyle and Henderson's (1984) findings. They posited that rules that are important to the members of the post-dissolutional relationship must be adhered to in order for the friendship to continue. Following the breaking of important rules, trust between the partners is damaged and the satisfaction with the friendship declines (West, 2006). If important rules continue to not be followed or are broken, the quality of the friendship will suffer and could lead to complete termination.

Whether a relationship is a romantic in nature, strictly platonic or a postdissolutional friendship, rules are important. They serve to guide behavior between the partners to maintain satisfaction in the relationship. While each type of relationship may have a general set of rules, the guidelines are fluid. Friendship rules are present in romantic relationships and post-dissolutional relationships. The same is true for romantic rules. All the rules in romantic relationships are not strictly romantic rules. Friendship rules are present in all types of relationships in order to guide behavior. With this understanding, implications need to be discussed.

\section{Implications}

With all of the new findings in this study and affirmations of past research, two critical implications exist for post-dissolutional friendships rule classification and postdissolutional relationship research as a whole. Because each individual differs in personal experiences, rules will not be the same for every dyad; however, this research begins to define some of the rules present in many post-dissolutional friendships. Given our expectations and rules are partly based on societal norms, there are some similarities in 
the types of rules that all post-dissolutional relationships follow and we can begin to make some generalizations.

First, we need to look at the nature of the distinctly post-dissolutional friendship rules. These rules become a hybrid of maintenance and intimacy-reward rules. Three out of the 10 post-dissolutional rules that participants cited could be classified as both maintenance and intimacy-reward relationships. This could be due to the fact that members of post-dissolutional relationships are always aware of their past romantic relationships. This amorous legacy could lead to possible problems with maintaining a platonic friendship. Post-dissolutional friendship dyads must have a heightened awareness of maintenance rules and following of them in order to keep the relationship together. Partners must navigate how to respect privacy, discover how much time to spend talking to each other and find ways to reduce sources of friction to keep the relationship afloat. Maintenance behaviors must be intentionally performed in postdissolutional friendships. At the same time that maintenance rules are being performed, so too must intimacy-reward rules. These rules set boundaries for displays of support, comfort, and affection that partners show to each other. These rules must be followed in order to quell lingering romantic feelings that could lead to jealousy and hurt. The performance of these behaviors leads to a following of maintenance, intimacy-reward rules, and a hybrid of the two.

The categorization of rules as either maintenance or intimacy-reward rules seems to be flawed. It seems that all rules are inherently maintenance rules but only some are intimacy-reward rules. This leads me to question how loosely Argyle and his colleagues defined maintenance and intimacy-reward rules. Because of the vast amount of research 
that has been conducted since Argyle originally conceived of these definitions, it is necessary for scholars to go back and analyze if these categories are really the most effective to describe rules.

Second, there are numerous benefits to continued friendship after a break-up, but we must also be aware of the dark side of post-dissolutional friendships. Postdissolutional friendships are a tricky territory to navigate if partners have different intentions. Some partners may be motivated to form a friendship with an ex partner to become romantically involved again. In the same manner, the formation of postdissolutional friendships may threaten the development of new romantic relationships. Unclear intentions create an unfortunate situation for both partners and could lead to the complete termination of the post-dissolutional relationship. Thus, the need for open and honest communication in post-dissolutional friendships becomes increasingly important.

Third, the increased use of digital channels for post-dissolutional communication brings out new problems. Former romantic partners may feel the need to continue to be friends with their former partners out of pressure of their social network or their former partner. In order to portray a positive image online, ex-partners may continue to communicate with their former dating partners. This then brings into question the idea of what a post-dissolutional "friendship" really is? If an individual is only talking to their former romantic partner because they feel social pressure (or pressure from their former partner) to remain "friends," is this relationship truly representative of a postdissolutional friendship? It appears that post-dissolutional friendship has to have positive intent from both members of the former dating relationship. Perhaps, then, this brings up the need of further delineations of post-dissolutional relationships beyond just post- 
dissolutional friendships. Now that implications have been discussed, limitations of the current study can be examined and then some areas for future research will discussed.

\section{Limitations}

Several limitations existed within this study. The first of which was the participant pool. Participants were recruited using the author's social media accounts and the school of communication research pool and as such, the majority of participants had similar demographics. It would have been beneficial to have a sample of participants that was more diverse in terms of age, race, and sexual orientation.

A large percentage of the sample was in their twenties. Had the participants been more diverse in terms of age range, I may have been able to study post-dissolutional relationships that have lasted for many years. It is possible that the length of the relationship could have had an effect on the continued desire for post-dissolutional communication. Additionally, it is not known if participants reported on post-divorce relationships. The rules may have been somewhat different if the sample included divorced co-parents.

While friendship rules have been very well defined, romantic relationship rules have not. Had there been a more agreed upon list of romantic relationship rules, some of the results of this study may have changed. While more friendship rules were followed in post-dissolutional friendships, perhaps that may have changed with additional romantic rules. Romantic relationship rules must continue to be studied in order to garner a more comprehensive set of relational rules.

This study could have been improved if both members of the post-dissolutional friendship had been participants. The fourth section asked participants to report on how 
often they believed their partner followed the rules. It is completely possible that this was not an accurate representation of the rules that participants' partners actually followed.

Lastly, because of the qualitative nature of the questions regarding distinctive post-dissolutional friendship rules, the importance was not based on very many ratings. Ratings were given from as few as one participant up to seven. The ratings of importance could only be collected if the participant suggested a new rule not found on the survey instrument. Thus, several of the new rules only had a few ratings of importance instead of the full sample. These rules would need to be rated on a scale of importance with a larger survey pool to ensure generalizability. With these limitations discussed, suggestions for future research can now be made.

\section{Suggestions for Future Research}

Although there have been numerous studies examining various topics within postdissolutional friendships, there are several directions that future research could go in. Specifically, research needs to be compiled on varying types of post-dissolutional relationships, post-dissolutional relationships in the digital age, and LGBT postdissolutional friendships. The reason for forming a friendship with a former romantic partner varies for every person. Some post-dissolutional relationships form because partners must remain interdependent after the romantic relationship has ended for their children while others form friendships because the dyadic partners cannot imagine being disconnected from each other.

Specifically, post-divorce relationships or post-dissolutional friendships that have resulted following the co-creation of offspring are an incredibly ripe area of study. Given the prevalence of divorce and mixed families, scholars need to study how divorcees or 
post-dissolutional friendship partners maintain communication and why. Masheter (1990) argues that "the quality of life after divorce for both adults and children clearly depends on whether children have contact with both parents and the quality of that contact" (p. 116). Rules in these types of relationships may often be modified to consider the needs of children produced during the relationship. The inclusion of new spouses or stepchildren may also provide interesting research in terms of post-dissolutional communication. The relationship between members of post-divorce friendships is essential to how the family functions and thus is deserving of further research (Ahrons, 1981).

Another possible area for continued study of post-dissolutional relationships is examining post-dissolutional friendships in the digital realm. In order to aid in the everchanging nature of how people stay in touch, communication scholars who wish to further examine post-dissolutional friendships should consider using computer mediated communication to guide their research. Whether partners decide to separate because of distance or other reasons, many communicate mostly or exclusively online. For these types of relationships, one could examine post-dissolutional friendships using the hyperpersonal model. Do individuals start to hyperpersonalize each other after they have not seen each other face-to-face? Additionally, rules' regarding appropriate postdissolutional communication online is an untouched area that needs to be studied. Is it possible that a new set of relational rules exists for computer mediated communication? This channel of communication among post-dissolutional friendship partners should be further examined, especially since a growing number of individuals choose to continue communication with former partners via online interactions. 
Lastly, the vast majority of current post-dissolutional relationship research relies on a primarily heterosexual population (Lannutti \& Cameron, 2002, being a noted exception). Generalizations about post-dissolutional friendships cannot be made without including a sampling of various orientations. While it may be more difficult to find diverse populations for study, an effort to study same-sex post-dissolutional relationships needs to be made. Studies primarily examining post-dissolutional friendships within homosexual relationships will further aid in understanding why various types of people continue to communicate after a break-up.

\section{Conclusion}

The study of post-dissolutional friendship is relatively new. Just like romantic relationships and friendships, post-dissolutional friendships are guided by maintenance

and intimacy-reward rules. This study sought to find what romantic relationship rule and friendship rules are at play in post-dissolutional friendships. Both sets of rules are present and play an integral role in guiding behaviors. This study also created a list of postdissolutional friendship rules that are neither friendship nor romantic relationship rules.

Because of the distinct nature of post-dissolutional friendships, maintenance rules become especially important. Maintenance rules serve to keep the relationship from lapsing by mitigating possible sources of friction. Individuals rate maintenance rules as more important than intimacy-reward rules in their post-dissolutional relationships. Additionally, individuals report that their partners follow maintenance rules more often than intimacy-reward rules.

In the same way that romantic relationships and friendships differ in quality, so too do post-dissolutional friendships. Previous research suggested that the quality of 
relationships was positively related to how well relational rules are followed and postdissolutional relationships were no different. The quality of post-dissolutional friendships was positively correlated to how well relational partners adhered to rules that participants deemed important. 


\section{REFERENCES}

Ahrons, C. (1981). The continuous coparental relationship between divorced spouses. American Journal of Orthopsychiatry, 51, 413-429. doi: 10.1111/j.19390025.1981.tb01390.x

Argyle, M. Graham, J., Campbell, A., \& White, P. (1979). The rules of different situations. New Zealand Psychologist, 8(1), 13-22. http://www.psychology.org.nz/

Argyle, M., \& Henderson, M. (1984). The rules of friendship. Journal of Social and Personal Relationships, 1, 211-237. doi: 10.1177/0265407584012005

Argyle, M., \& Henderson, M. (1985). The rules of relationships. In S. Duck \& D. Perlman (Eds.), Understanding personal relationships: An interdisciplinary approach (pp. 63-84). Beverly Hills, CA: Sage.

Baxter, L. (1986). Gender differences in the heterosexual relationship rules embedded in break-up accounts. Journal of Social and Personal Relationships, 3, 289-306. doi: $10.1177 / 0265407586033003$

Baxter, L., Mazanec, M., Nicholson, J., Pittman, G., Smith, K., \& West, L. (1997). Everyday loyalties and betrayals in personal relationships. Journal of Social and Personal Relationships, 14, 655-678. doi: 10.1177/0265407597145005

Banks, S., Altendorf, D., Greene, J., \& Cody, M. (1987). An examination of relationship disengagement: Perceptions, break-up strategies, and outcomes. Western Journal of Speech Communication, 51, 19-41. doi: 10.1080/1057031870937425

Busboom, A., Collins, D., Givertz, M., \& Levin, L. (2002). Can we still be friends? Resources and barriers to friendship quality after romantic relationship dissolution. Personal Relationships, 9, 215-223. doi: 10.1111/1475-6811.0001

Cushman, D. (1977). The rules perspective as a theoretical basis for the study of human communication. Communication Quarterly, 25(1), 30-45. doi: $10.1080 / 01463377709369245$

Cushman, D., \& Whiting, G. (1972). An approach to communication theory: Toward consensus on rules. Journal of Communication, 22, 217-238. doi: 10.1111/j.14602466.1972.tb00149x 
Graham, E. (1997). Turning points and commitment in post divorce relationships.

Communication Monographs, 64, 350-369. doi: 10.1080/03637759709376428

Jones, E., \& Gallois, C. (1989). Spouses' impressions of rules for communication in public and private marital conflicts. Journal of Marriage and the Family, 51, 957967. http://www.jstor.org/stable/353208

Koenig Kellas, J., Bean, D., Cunningham C., \& Cheng, K. (2008). The ex-files: Trajectories, turning points, and adjustment in the development of postdissolutional relationships. Journal of Social and Personal Relationships, 25, 2350. doi: 10.1177/0265407507086804

Lambert, A., \& Hughes, P. (2010). The influence of goodwill, secure attachment, and positively toned disengagement strategy on reports of communication satisfaction in non-marital post-dissolution relationships. Communication Research Reports, 27, 171-183. doi: 10.1080/08824091003738123

Lannutti, P., \& Cameron, K. (2002). Beyond the break-up: Heterosexual and homosexual post-dissolutional relationships. Communication Quarterly, 50, 153-170. doi: $10.1080 / 01463370209385654$

Masheter, C. (1990). Post divorce relationships between exspouses: A literature review. Journal of Divorce and Remarriage, 14, 97-122. doi: 10.1300/J087v14n01_08

Metts, S., Cupach, W., \& Bejlovec, R. (1989). "I love you too much to ever start liking you”: Redefining romantic relationships. Journal of Social and Personal Relationships, 6, 259-274. doi: 10.1177/0265407589063002

Salovey, P., \& Rodin, J. (1989). Envy and jealousy in close relationships. In C. Hendrick (Ed.), Review of personality and social psychology (pp. 221-246). Beverly Hills, CA: Sage.

Schneider, C., \& Kenny, D. (2000). Cross-sex friends who were once romantic partners: Are they platonic friends now? Journal of Social and Personal Relationships, 17, 451-466. doi: 10.1177/0265407500173007

Shimanoff, S. (1980). Communication rules: Theory and research. Beverly Hills, CA: Sage.

West, A. (2006). Relational standards: Rules and expectations in romantic relationships (Doctoral Dissertation). Retrieved from Australian Catholic University Digital Theses Database. http://dlibrary.acu.edu.au/digitaltheses/public/adtacuvp135.05022007/02chapters 1-11.pdf 
Wheeless, L. (1976). Self-disclosure and interpersonal solidarity: Measurement, validation, and relationships. Human Communication Research, 3, 47-61. doi: 10.1111/j.1468-2958.1976.tb00503.x

Wheeless, L., Wheeless, V., \& Baus, R. (1984). Sexual communication satisfaction, communication satisfaction, and solidarity in the developmental stages of intimate relationships. Western Journal of Speech Communication, 48, 217-230. doi: $10.1080 / 10570318409374158$ 


\section{APPENDIX A}

\section{HIGHLY ENDORSED FRIENDSHIP RULES}

1. Should address the other person by their first name.

2. Should not disclose to the other person one's feelings and personal problems. *

3. Should not ask the other for personal advice. *

4. Should not criticize the other person publicly.

5. Should stand up for the other person in their absence.

6. Should not discuss that which is said in confidence with the other person.

7. Should not indulge in sexual activity with the other person.

8. Should seek to repay debts, favor or compliments no matter how small.

9. Should not engage in joking or teasing with the other person. *

10. Should share news of success with the other person.

11. Should respect the other's privacy.

12. Should look the other person in the eye during conversation.

13. Should be emotionally supportive.

14. Should not nag the other person.

15. Should look after the other person when they are ill.

16. Should be tolerant of each other's friends.

18. Should trust and confide in one another.

19. Should volunteer help in time of need.

20. Should not be jealous or critical of other's relationships.

21. Should strive to make the other happy while in their company.

(* = the opposite of the stated rule is classified by respondents as very important)

Source: Argyle and Henderson (1984) 


\section{APPENDIX B}

\section{RULES THAT WERE FOUND TO BE VERY IMPORTANT IN CAUSING OF THE BREAK-UP OF A FRIENDSHIP}

1. Share news of success with the other.

2. Show emotional support.

3. Volunteer help in time of need.

4. Strive to make him/her happy while in each other's company.

5. Repay debts and favors.

6. Trust and confide in the other.

7. Stand up for the other person in their absence.

8. Be tolerant of other friends.

9. Don't criticize in public.

10. Keep confidences.

11. Don't be critical of other relationships.

12. Don't nag.

13. Respect privacy.

Source: Argyle and Henderson (1984) 


\section{APPENDIX C \\ SURVEY INSTRUMENT \\ Friendship with Former Dating Partners}

Following the break-up of romantic relationships, ex-partners may find themselves desiring continued connection. Former partners who choose to maintain contact with their ex-partners often structure this new association as a 'friendship.' These relationships are known as post-dissolutional friendships. This survey is being used to gather information about your current post-dissolutional friendship.

\section{Relationship Information}

Please answer the following questions regarding your current post-dissolutional friendship. If you have more than one current post-dissolutional friendship, please answer questions for only one of your post-dissolutional friendships.

1. How long have you been friends with a former dating partner after the break-up? years months

2. How long was the dating portion of your post-dissolutional relationship? years months

3. Were you friends prior to dating? Yes

No

4. Are you currently in a romantic relationship? If so how long have you been in a romantic relationship?

Yes

No years months

5. How often do you communicate with your former dating partner?

At least once a day A few times a week Once a week A few times a month Once a month Other (please specify) 


\section{Norms in post-dissolutional friendships}

Relationships follow a set of rules or norms to guide behavior. Below is a list of rules that may or may not be present in your post-dissolutional relationship. Please identify how important these rules are to you in your current post-dissolutional friendship. In other words, how important is it to you that your partner follows each of these important rules in order to have a satisfying relationship
1. Should disclose to the other person one's feelings and personal problems.

\begin{abstract}
2
\end{abstract}
Not Important
4
Somewhat Important
6 7
Very Important 1

2. Should ask the other for personal advice.

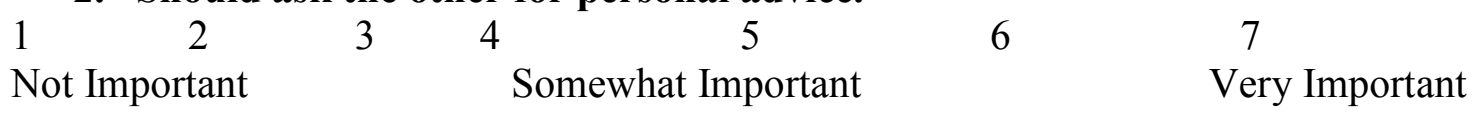

3. Should not criticize the other person publicly.

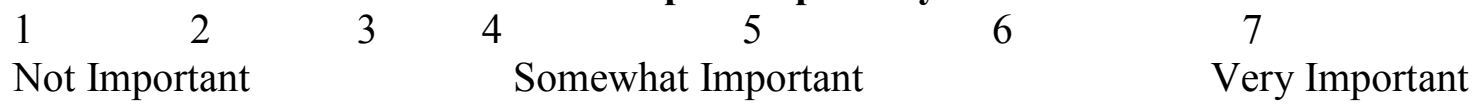

4. Should stand up for the other person in their absence.

$\begin{array}{llllllll}1 & 2 & 3 & 4 & 5 & 6 & 7\end{array}$

Not Important Somewhat Important Very Important

5. Should not discuss that which is said in confidence with the other person.

$\begin{array}{lllllll}1 & 2 & 3 & 4 & 5 & 6 & 7\end{array}$

Not Important Somewhat Important Very Important

6. Should not indulge in sexual activity with the other person.

\begin{tabular}{|c|}
\hline $\begin{array}{l}1 \\
\text { Not Important }\end{array}$ \\
\hline
\end{tabular}

7. Should seek to repay debts.

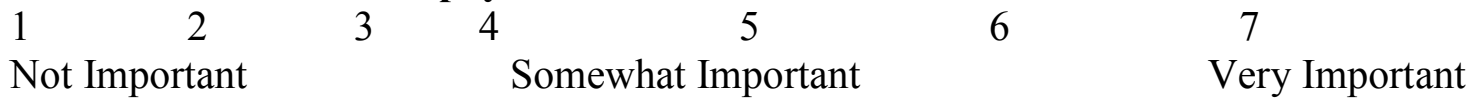

8. Should seek to repay favor.

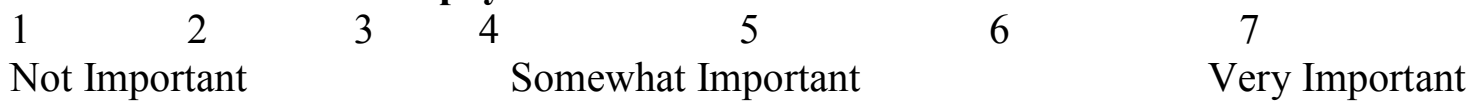

9. Should share news of success with the other person.

$\begin{array}{llllllll}1 & 2 & 3 & 4 & 5 & 6 & 7\end{array}$

Not Important Somewhat Important Very Important 
21. Should not discuss sexual encounters with the other.

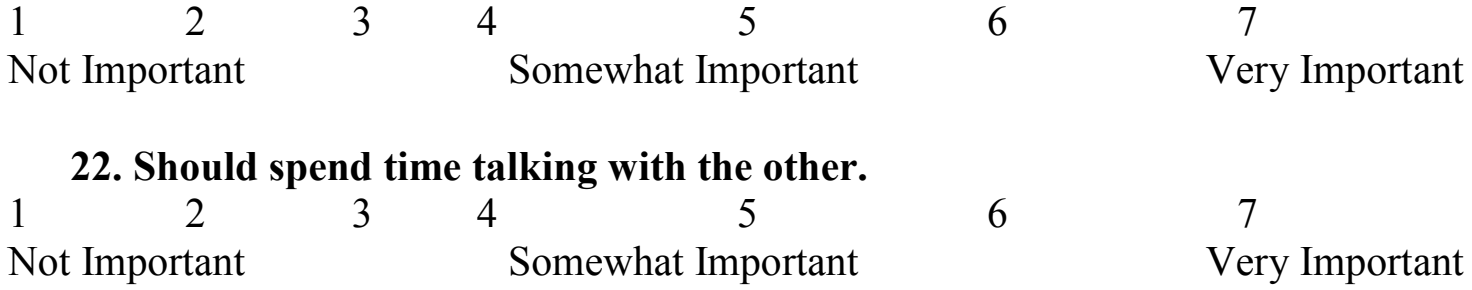

\section{Open-Ended}

1. You have just responded to a list of rules that may potentially apply in your post-dissolutional relationship. It is highly possible that you and your postdissolutional partners have rules that weren't listed. If there are any rules that you and your partner find important, briefly describe them below. Please Identify up to three rules

2. How important are the rules that you listed above?

1 2

\section{Extent to Which Rules are Followed}

What follows is a list of the same rules as in the previous section. For this set, please indicate to what extent your current post-dissolutional friend adheres to the following rules.

1. Should disclose to the other person one's feelings and personal problems.

12

Never
3

Sometimes
4 Always
5

2. Should ask the other for personal advice. 1

Never

Sometimes
4 Always

3. Should not criticize the other person publicly. 1 2 3

4. Should stand up for the other person in their absence. 1 Never
2

3

Sometimes
4

Always 
5. Should not discuss that which is said in confidence with the other person. 1

Never

2

3

Sometimes

Always

6. Should not indulge in sexual activity with the other person.

1

Never
2

3

Sometimes
4

Always
5

7. Should seek to repay debts.

1

Never
3

Sometimes
4

Always

8. Should seek to repay compliments.

1

Never
3

Sometimes
4

Always

9. Should share news of success with the other person. 1

Never
2

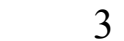

Sometimes
4

Always

10. Should respect the other's privacy.

1

Never
3

Sometimes
5 


\section{Should not be jealous or critical of other's relationships.}

1

2

3

4

5

Never

Sometimes

Always

17. Should strive to make the other happy while in their company.

1

Never

2

3

Sometimes

4

Always

5

18. Should try to resolve conflict.

1

Never

3

Sometimes
4

Always

19. Should maintain positivity in interactions.

1

Never
2

4

Sometimes

5

Always

20. Should be tolerant of each other's romantic relationships.

1

Never
2

3

Sometimes
4

Always

5 
3. I trust this person completely.

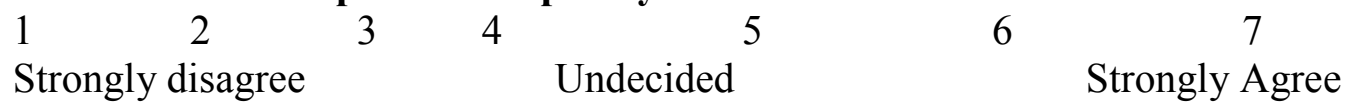

4. We feel very differently about most things.

$\begin{array}{llllccc}1 & 2 & 3 & 4 & 5 & 6 & 7 \\ \text { Strongly disagree } & & & \text { Undecided } & \text { Strongly Agree }\end{array}$

5. I willingly disclose a great deal of positive and negative things about myself, honestly, and fully (in depth) to this person.

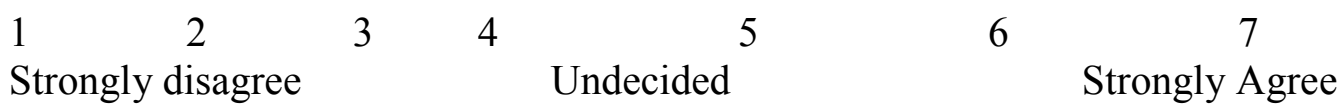

6. We do not really understand each other.

$\begin{array}{lcccccc}1 & 2 & 3 & 4 & 5 & 6 & 7 \\ \text { Strongly disagree } & & & \text { Undecided } & \text { Strongly Agree }\end{array}$

7. This person willingly discloses a great deal of positive and negative things about him/herself, honestly and fully (in depth) to me.

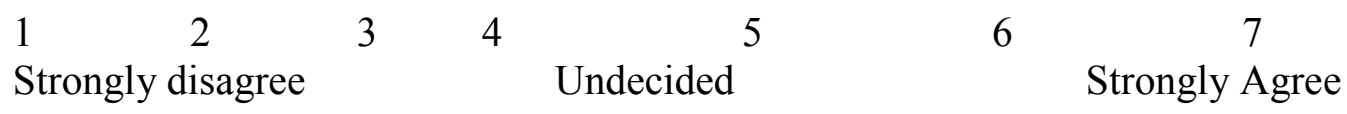

8. I distrust this person.

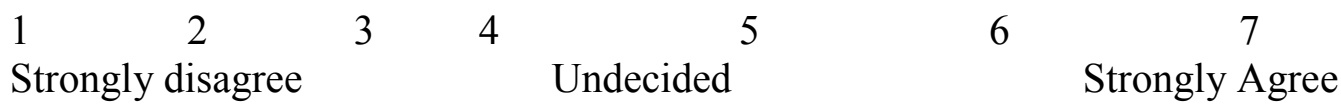

9. I like this person much more than most people I know.

$\begin{array}{lcccccc}1 & 2 & 3 & 4 & \text { Undecided }^{5} & 6 & 7 \\ \text { Strongly disagree } & & & & \text { Strongly Agree }\end{array}$

10. I seldom interact/communicate with this person.

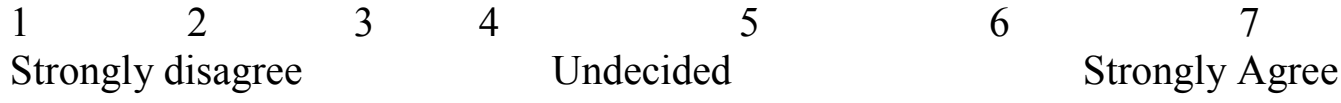

11. I love this person.

$\begin{array}{lcccccc}1 & 2 & 3 & 4 & \text { Undecided }^{5} & 6 & 7 \\ \text { Strongly disagree } & & & & \text { Strongly Agree }\end{array}$

12. I understand this person and who $\mathrm{s} / \mathrm{he}$ really is.

$\begin{array}{lcccccc}1 & 2 & 3 & 4 & \text { Undecided }^{5} & 6 & 7 \\ \text { Strongly disagree } & & & & & \text { Strongly Agree }\end{array}$




\section{I dislike this person.}

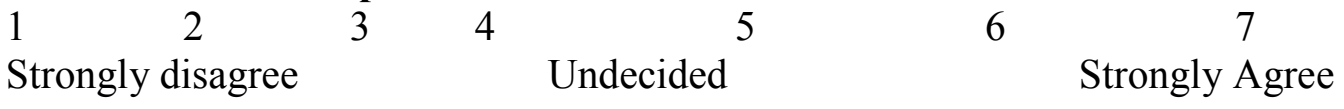

14. I interact/communicate with this person much more than with most people I know.

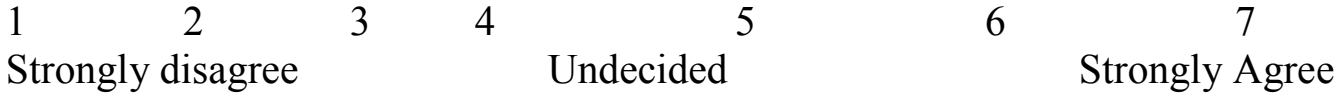

15. We are not very close at all.

$\begin{array}{lcccccc}1 & 2 & 3 & 4 & 5 & 6 & 7 \\ \text { Strongly disagree } & & & \text { Undecided } & & & \text { Strongly Agree }\end{array}$

16. We share a lot in common.

$\begin{array}{lcccccc}1 & 2 & 3 & 4 & 5 & 6 & 7 \\ \text { Strongly disagree } & & & \text { Undecided } & & & \text { Strongly Agree }\end{array}$

17. We do a lot of helpful things for each other.

$\begin{array}{lllllll}1 & 2 & 3 & 4 & \text { Undecided }^{5} & 6 & 7 \\ \text { Strongly disagree } & & & \text { Undrongly Agree }^{2}\end{array}$

18. I have little in common with this person.

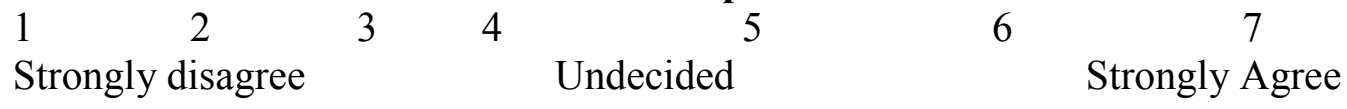

19. I feel very close to this person.

$\begin{array}{lcccccc}1 & 3 & 4 & 5 & 6 & 7 \\ \text { Strongly disagree } & & & \text { Undecided }^{5} & & \text { Strongly Agree }\end{array}$

20. We share some private way(s) of communicating with each other.

$\begin{array}{lclllll}1 & 2 & 3 & 4 & \text { Undecided }^{5} & 6 & 7 \\ \text { Strongly disagree } & & & \text { Undrongly Agree }^{2}\end{array}$

\section{Demographic Information}

To end, we would like to get some information about you. Your answers to these questions will help us better understand the opinions you express in other sections of this questionnaire.

1. What is your sex? 1. Male 2. Female (please circle one)

2. What is the sex of your post-dissolutional friendship partner?

1. Male 2. Female 3. Prefer not to disclose (please circle one) 
3. What was your age on your last birthday?

4. What was your friend's age on his/her last birthday?

5. What is your ethnicity? Check all that apply.

African American Asian Caucasian/White Hispanic/Latino Multiracial

Native American Pacific Islander I don't want to disclose

Other 